\title{
EDITORIAL
}

\section{Genome-wide expression profiling of T-cells in childhood wheeze}

\author{
A. Bosco and P.G. Holt
}

lucidation of the molecular mechanisms underlying asthma and related phenotypes is a monumental task. To date, $>100$ susceptibility genes have already been identified with diverse functions. These can broadly be classified into those involved in the regulation of the innate and adaptive immune system, epithelial biology, lung function and remodelling, and disease severity [1]. An important advance that has the potential to accelerate progress in this area is the emergence of microarray-based expression profiling technology that enables the systematic, genome-wide analysis of the transcriptional changes underlying cellular behaviour and functionality. This new technology has already revealed important insights into asthma pathogenesis in experimental animal models $[2,3]$ but has yet to be exploited to a significant degree in the context of human asthma. In the current issue of the European Respiratory Journal, the study by KAPITEIN et al. [4] focuses on CD4 T-cell phenotypes associated with childhood wheeze, which represents a significant initial step in this direction.

CD4 T-cells, especially T-helper (Th)2-polarised effectors, are acknowledged to be major players in the pathogenesis of human asthma [1]. Previous studies have demonstrated that Th2 cytokine production is elevated in airway CD4 T-cells in both atopic and nonatopic forms of the disease [5, 6]. Moreover, levels of expression of Th2 cytokines by airway CD4 T-cells correlate with disease severity [7]. Findings in blood, whilst not always reproducing those in the airways $[7,8]$, have demonstrated that $\mathrm{T}$-cell response patterns are, to some degree, predictive of the later development of wheeze [9]. Importantly, heterogeneity in blood T-cell response patterns is associated with variable expression of asthma/wheeze versus bronchial hyperreactivity [10], suggesting that there are covert relationships between asthma-related phenotypes and underlying immunological phenotypes.

A limitation of these earlier studies, imposed by the technology available at the time, was the restricted number of T-cellassociated genes investigated, because it is now recognised that hundreds of genes participate in T-cell responses, including Th2 responses against asthma-associated antigens

Telethon Institute for Child Health Research, Centre for Child Health Research, Faculty of Medicine and Dentistry, The University of Western Australia, Perth, Australia.

STATEMENT OF INTEREST: None declared.

CORRESPONDENCE: P.G. Holt, Telethon Institute for Child Health Research, Centre for Child Health Research, Faculty of Medicine and Dentistry, The University of Western Australia, Perth, Australia. Fax:61894897707.E-mail: patrick@ichr.uwa.edu.au
$[11,12]$. The study by KAPITEIN et al. [4] begins the long process towards redressing this deficiency by applying microarray technology in a preliminary investigation of gene expression profiles in blood CD4 T-cells from children with transient and persistent wheeze. The blood samples used were obtained in the absence of current symptoms; therefore, the data should reflect variations in baseline gene expression in T-cells in the absence of active inflammation.

The data from the study by KAPITEIN et al. [4] demonstrates that there were similarities in the differential gene expression signatures in both transient and persistent wheezers relative to healthy controls, suggesting that similar mechanisms may be operating in these distinct phenotypes. This "common" expression signature includes the highly conserved heat shock proteins (hsp), which are induced in conditions of cellular stress and inflammation and are implicated in T-cell regulation of chronic inflammation [13]. Several mechanisms relevant to airways inflammation are likely to be susceptible to control by endogenous hsp. In particular, regulatory T-cell (Treg) function, which can be enhanced via hsp-mediated activation of TLR signalling pathways on Treg [14], and an additional Treg subset that can be triggered directly by self hsp [13]. In the common expression signature, the upregulation of natural killer (NK) cellassociated markers was also prominent, of which CD226 has previously been reported to be elevated in NK T-cells from asthma patients [15] and may constitute an innate immune-axis driving disease pathogenesis $[16,17]$. The Th2 regulators CISH [18] and CD27RA [19] also featured in the common gene signature upregulated in both wheezing phenotypes.

The T-cell profile from transient wheezers was characterised by a reduced expression of genes involved in interferon signalling and oxidate stress (glutathione S-transferase M1; GSTM1). A deficiency of these two pathways has previously been implicated in the susceptibility of the asthmatic epithelium to viral infection [20] and oxidative damage [21]. In this context it is noteworthy that transcriptional profiling of lymphocytes can reveal general insights into gene expression, which is also relevant to genes that primarily function in other cell types [22]. An additional finding of interest was upregulation of annexin-A1 (also known as lipocortin) in the transient wheezers. Annexin-A1 is an antiinflammatory protein currently thought to mediate some of the anti-inflammatory activities of corticosteroids on innate immune cells; however, paradoxically, annexin-A1 signalling can enhance T-cell activation pathways [23].

Analysis of gene expression patterns in T-cells isolated from persistent wheezers highlighted a deficiency in expression of 
the prostaglandin $(\mathrm{PG}) \mathrm{E}_{2}$ receptor subtype EP2 (PTGER2). Inhalation of $\mathrm{PGE}_{2}$ prior to allergen challenge in humans in vivo attenuated asthma-related symptoms in the airways [24]. PTGER2 signalling may have a dual protective role in asthma, promoting relaxation of airway smooth muscle [25] and enhancing the function of Treg via the induction of FoxP3 $[26,27]$. Finally, several of the genes highlighted in the study by KAPITEIN et al. [4] (arachidonate 5-lipoxygenase, GSTM1 and PTGER2) harbour polymorphisms relevant to the pathogenesis of asthma and response to therapy [1,28], suggesting that gene expression profiling studies in lymphocytes may be exploited to select logical candidates for follow-up in genetic studies [22].

The study by KAPITEIN et al. [4] has several limitations which should be acknowledged when interpreting the overall findings. Gene expression is highly variable in human subjects [29], thus moderate sample sizes are essential in such studies. Therefore, the findings of KAPITEIN et al. [4], in a relatively small study group, must be replicated in an independent and larger sample. More importantly, the study population was heterogeneous with respect to sex, atopic status, family history of asthma/atopy and use of medications at the time of blood sampling, which may have confounded the analyses. It is also noteworthy that there is limited overlap in the gene lists reported in expression profiling studies of asthma [30]. In particular, expression of Th2 signature genes [11, 12] was not a prominent feature in the results of the study by KAPITEIN et al. [4]. However, this may be a methodology issue, as it has been reported that expression of Th2-related genes in resting circulating CD4 T-cells from atopic asthmatic adults is undetectable by microarray but can be readily identified by more sensitive quantitative RT-PCR [31]. It is also possible that even if T-cells are major contributors to the airway pathology underlying wheeze, the differences between affected and healthy subjects in relevant expression profiles of circulating T-cells may, nevertheless, only manifest following activation by relevant environmental triggering agents (e.g. allergen or virus). Moreover, there are few studies on which to base an estimate of how long such triggering-induced changes in gene expression may persist in circulating T-cells following a wheezing event. The logical approach to addressing these complexities is to track groups of subjects prospectively. KAPITEIN et al. [4] have stated that this is their preferred follow-up strategy.

Notwithstanding these limitations, the preliminary study by KAPITEIN et al. [4] provides the first published evidence that the baseline gene expression programme may be altered in blood CD4 T-cells in wheezers relative to that in healthy controls and, moreover, may vary between different wheezing phenotypes. The microarray technology demonstrated herein has great potential to elucidate this and related issues, employing variations of the utilised study structure. Casting the net wider to include profiling of other effector-cell populations implicated in airways inflammation, in particular CD8 T-cells and monocytes, would represent a logical extension of this promising approach.

\section{REFERENCES}

1 Vercelli D. Discovering susceptibility genes for asthma and allergy. Nat Rev Immunol 2008; 8: 169-182.
2 Kuperman DA, Lewis CC, Woodruff PG, et al. Dissecting asthma using focused transgenic modeling and functional genomics. J Allergy Clin Immunol 2005; 116: 305-311.

3 Zimmermann N, Mishra A, King NE, et al. Transcript signatures in experimental asthma: identification of STAT6-dependent and -independent pathways. J Immunol 2004; 172: 1815-1824.

4 Kapitein B, Hoekstra MO, Nijhuis EHJ, et al. Gene expression in CD4+ T-cells reflects heterogeneity in infant wheezing phenotypes. Eur Respir J 2008; 32: 1203-1212.

5 Humbert M, Durham SR, Ying S, et al. IL-4 and IL-5 mRNA and protein in bronchial biopsies from patients with atopic and nonatopic asthma: evidence against "intrinsic" asthma being a distinct immunopathologic entity. Am J Respir Crit Care Med 1996; 154: 1497-1504.

6 Ying S, Humbert M, Barkans J, et al. Expression of IL-4 and IL-5 mRNA and protein product by CD4+ and CD8+ T cells, eosinophils, and mast cells in bronchial biopsies obtained from atopic and nonatopic (intrinsic) asthmatics. J Immunol 1997; 158: 3539-3544.

7 Cho SH, Stanciu LA, Holgate ST, Johnston SL. Increased interleukin-4, interleukin-5, and interferon- $\gamma$ in airway CD4+ and CD8+ T cells in atopic asthma. Am J Respir Crit Care Med 2005; 171: 224-230.

8 Hartl D, Koller B, Mehlhorn AT, et al. Quantitative and functional impairment of pulmonary CD4+CD25hi regulatory $\mathrm{T}$ cells in pediatric asthma. J Allergy Clin Immunol 2007; 119: 1258-1266.

9 Stern DA, Guerra S, Halonen M, Wright AL, Martinez FD. Low IFN- $\gamma$ production in the first year of life as a predictor of wheeze during childhood. J Allergy Clin Immunol 2007; 120: 835-841.

10 Heaton T, Rowe J, Turner S, et al. An immunoepidemiological approach to asthma: identification of in vitro T-cell response patterns associated with different wheezing phenotypes in children. Lancet 2005; 365: 142-149.

11 Bosco A, McKenna KL, Devitt CJ, Firth MJ, Sly PD, Holt PG. Identification of novel Th2-associated genes in T memory responses to allergens. J Immunol 2006; 176: 4766-4777.

12 Lund RJ, Loytomaki M, Naumanen T, et al. Genome-wide identification of novel genes involved in early Th1 and Th2 cell differentiation. J Immunol 2007; 178: 3648-3660.

13 van Eden W, van der Zee R, Prakken B. Heat-shock proteins induce $\mathrm{T}$-cell regulation of chronic inflammation. Nat Rev Immunol 2005; 5: 318-330.

14 Zanin-Zhorov A, Cahalon L, Tal G, Margalit R, Lider O, Cohen IR. Heat shock protein 60 enhances CD4+ CD25+ regulatory $\mathrm{T}$ cell function via innate TLR2 signaling. J Clin Invest 2006; 116: 2022-2032.

15 Sen Y, Yongyi B, Yuling H, et al. V alpha 24-invariant NKT cells from patients with allergic asthma express CCR9 at high frequency and induce Th2 bias of CD3+ T cells upon CD226 engagement. J Immunol 2005; 175: 4914-4926.

16 Akbari O, Faul JL, Hoyte EG, et al. CD4+ invariant T-cellreceptor+ natural killer T cells in bronchial asthma. $N$ Engl J Med 2006; 354: 1117-1129.

17 Kim EY, Battaile JT, Patel AC, et al. Persistent activation of an innate immune response translates respiratory viral infection into chronic lung disease. Nat Med 2008; 14: 633-640. 
18 Matsumoto A, Seki Y, Kubo M, et al. Suppression of STAT5 functions in liver, mammary glands, and $\mathrm{T}$ cells in cytokine-inducible $\mathrm{SH} 2$-containing protein 1 transgenic mice. Mol Cell Biol 1999; 19: 6396-6407.

19 Yoshimoto T, Yoshimoto T, Yasuda K, Mizuguchi J, Nakanishi K. IL-27 suppresses Th2 cell development and Th2 cytokines production from polarized Th2 cells: a novel therapeutic way for Th2-mediated allergic inflammation. J Immunol 2007; 179: 4415-4423.

20 Contoli M, Message SD, Laza-Stanca V, et al. Role of deficient type III interferon-lambda production in asthma exacerbations. Nat Med 2006; 12: 1023-1026.

21 Yang IA, Fong KM, Zimmerman PV, Holgate ST, Holloway JW. Genetic susceptibility to the respiratory effects of air pollution. Thorax 2008; 63: 555-563.

22 Dixon AL, Liang L, Moffatt MF, et al. A genome-wide association study of global gene expression. Nat Genet 2007; 39: 1202-1207.

23 D'Acquisto F, Merghani A, Lecona E, et al. Annexin-1 modulates T-cell activation and differentiation. Blood 2007; 109: 1095-1102.

24 Gauvreau GM, Watson RM, O'Byrne PM. Protective effects of inhaled PGE2 on allergen-induced airway responses and airway inflammation. Am J Respir Crit Care Med 1999; 159: 31-36.

25 Chung KF. Evaluation of selective prostaglandin E2 (PGE2) receptor agonists as therapeutic agents for the treatment of asthma. Sci STKE 2005; 2005: pe47.

26 Sharma S, Yang SC, Zhu L, et al. Tumor cyclooxygenase-2/ prostaglandin E2-dependent promotion of FOXP3 expression and CD4+ CD25+ T regulatory cell activities in lung cancer. Cancer Res 2005; 65: 5211-5220.

27 Baratelli F, Lin Y, Zhu L, et al. Prostaglandin E2 induces FOXP3 gene expression and $\mathrm{T}$ regulatory cell function in human CD4+ T cells. J Immunol 2005; 175: 1483-1490.

28 Drazen JM, Yandava CN, Dube L, et al. Pharmacogenetic association between ALOX5 promoter genotype and the response to anti-asthma treatment. Nat Genet 1999; 22: 168-170.

29 Morley M, Molony CM, Weber TM, et al. Genetic analysis of genome-wide variation in human gene expression. Nature 2004; 430: 743-747.

30 Hansel NN, Diette GB. Gene expression profiling in human asthma. Proc Am Thorac Soc 2007; 4: 32-36.

31 Hansel NN, Cheadle C, Diette GB, et al. Analysis of CD4+ $\mathrm{T}$-cell gene expression in allergic subjects using two different microarray platforms. Allergy 2008; 63: 366-369. 